\title{
A review on protection of DC microgrids
}

\author{
Lin ZHANG ${ }^{1}$, Nengling TAI ${ }^{1}$, Wentao HUANG ${ }^{1}$, Jian LIU $^{\mathbf{1}}$, \\ Yanhong WANG ${ }^{1}$
}

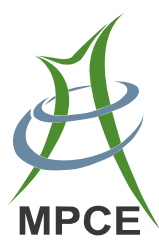

\begin{abstract}
The DC microgrid has become a typical distribution network due to its excellent performance. However, a well-designed protection scheme still remains a challenge for DC microgrids. At present, researches on DC microgrids primarily focus on the topology structure, control method and energy control, while researches on fault analysis, detection and isolation have not drawn enough attention. Therefore, this paper intends to depict the current research status in different relative areas and review the proposed protection strategies in order to help researchers to have a clear understanding on DC microgrid protection. Meanwhile, to solve the protection issues and promote the development of the DC microgrid, this paper points out the key areas of future research. The future protection research directions lie in the development of novel protection devices, which are based on electronic technology to provide loose protection constraints and the improvement of
\end{abstract}

CrossCheck date: 7 November 2017

Received: 29 December 2016/Accepted: 7 November 2017/ Published online: 12 March 2018

(C) The Author(s) 2018

$\triangle$ Wentao HUANG

hwt8989@sjtu.edu.cn

Lin ZHANG

linzhgee@foxmail.com

Nengling TAI

nltai@sjtu.edu.cn

Jian LIU

scut_liujian@163.com

Yanhong WANG

siliviaw@foxmail.com

1 School of Electronic Information and Electrical Engineering, Shanghai Jiao Tong University, Shanghai 200240, China suitable protection schemes. In addition, the novel concept of coordinated strategy of control and protection of the DC microgrids is explained.

Keywords DC microgrids, Protection devices, Fault characteristics, Grounding options, Protection schemes

\section{Introduction}

The concept of microgrids has been proposed in order to make good use of distributed energy resources (DERs). The development of DERs can effectively reduce the carbon emissions, while enhancing the power quality and reliability $[1,2]$. According to the power properties, microgrids can be divided into $\mathrm{AC}$ and $\mathrm{DC}$ microgrids. AC microgrids have been comprehensively researched because of the similarities to the traditional AC power system. Nowadays, the advantages shown within DC microgrids arouse increasing interests of scholars around the world. Compared to AC microgrids, DC microgrids require less conversion stages and transmit more DC power through a given cable. Moreover, DC systems are inherently efficient without any skin effect and can decrease line losses [3, 4].

High-voltage DC (HVDC) technologies have been utilized extensively, while the practical application of medium-voltage (MV) and low-voltage (LV) DC microgrids is just beginning. DC microgrids have been investigated in specific applications, including: (1) LV (up to $1.5 \mathrm{kV} \mathrm{DC}$ ) data centers [5] and LVDC distribution systems [6]; (2) MV (up to $35 \mathrm{kV} \mathrm{DC}$ ) systems on electric ships and also offshore wind power plants [7]. Realizing this potential, academic and industrial institutions are conducting projects around the world, for example FREEDM [8], UNIFLEX [9] and HEART [10]. They all aim to promote this technology at a new research level. 
In spite of the excellent characteristics of DC microgrids, effective fault protection schemes for DC microgrids still remain a challenge. In addition, protection standards and guidelines that can be widely accepted in industrial and commercial applications have not been proposed [11]. Some organizations have developed practical standards in specific fields such as the European standard ETSI EN 300 132-3-1 [12], IEEE Standard 946 [13] and IEC SG4 [14], which are respectively designed for data/telecom systems, DC auxiliary power systems and LVDC distribution systems. However, they did not reach a consensus and the widespread acceptance of standards still have a way to come. Due to the high magnitude and significant changing rate of the fault currents, fault detection and isolation should be evaluated as soon as possible. Previous researches indicate that typical voltage sourced converters (VSCs) can only tolerate twice the converter full-load current rating and the fault clearing time should be around $2 \mathrm{~ms}$ [3], [15]. In addition, the implementation of protection has to restrain the transient voltage and requires operating the devices in a coordinated way.

At present, studies on DC microgrids are primarily concerned with the topology structure, control method and energy management. The design of protection schemes for DC microgrids has not drawn enough attention. As a result, this paper intends to depict the current research status in order to help researchers to have a clear understanding on the protection issues of DC microgrids.

The organization of the paper is as follows. Section 2 gives an introduction about typical DC microgrids. In Section 3, current status is depicted in detail, including fault current response, protection devices, grounding options and simulation software of DC microgrids. Section 4 reviews proposed protection schemes and discusses the design of a protection system. Then research prospects are presented in Section 5. Finally, the conclusion is drawn in Section 6.

\section{DC microgrids}

\subsection{DC microgrids configuration}

A microgrid refers to an independent and autonomous system consisting of multiple distributed generators, energy storages, energy conversion devices, loads, monitors and protection devices. Thus this system is independently able to realize self-control, protection and management requirements. Microgrids can either be connected to the main grid or be isolated as an island [16]. Microgrids can be divided into AC, DC and AC-DC hybrid microgrids according to the differences of the bus form. A DC microgrid system primarily consists of those main components including sources, converters, energy storage and loads. The typical ring busbar structure of a DC microgrid is shown in Fig. 1.

Distributed generations in a DC microgrid are divided into AC and DC sources. Typical DC sources, such as photovoltaic arrays are connected to the DC bus via a DC/ DC converter. Similarly, wind turbine generators are preferably connected to the DC bus through an AC/DC converter and greatly reduce the conversion stage compared to being connected to an AC bus. Therefore, compared with the $\mathrm{AC}$ microgrids, the energy conversion stages are greatly simplified.

According to the sources and loads characteristics, $\mathrm{AC} /$ DC, DC/AC and DC/DC converters are required. Different converters are applied to connect different sources and loads in order to match the requirements such as nominal voltage, galvanic isolation and efficiency. In addition, DC microgrids have an advantage on conversion over AC microgrids. Generally, converters used in DC microgrids are much simpler as there are less conversion segments.

Due to the intermittent conditions of renewable sources, energy storage is necessary to balance the power transient response. Moreover, energy storage is responsible for power quality improvement and the emergency power supply [3]. Common energy storage devices include batteries, super capacitors and flywheels [17]. Flywheel devices have to be connected to a DC bus via a machine and converter while batteries and super capacitors can be connected directly.

DC microgrids are most suitable to supply sensitive electronic loads [3]. The power supply characteristics are of high availability thus they can match the demands of the lighting system, data and communication system as well as the safety system. Some DC loads have direct connection to the DC bus, while other DC loads and AC loads have to be fed through converters.

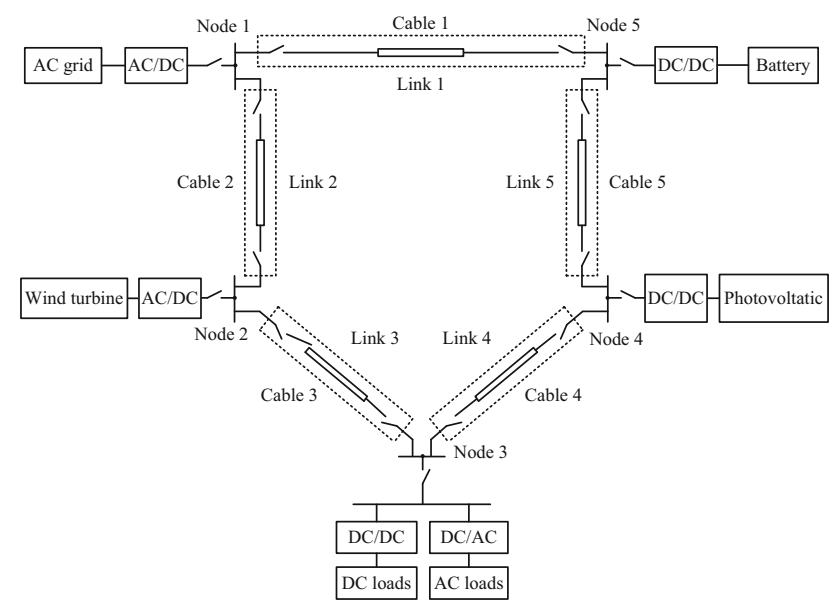

Fig. 1 Typical structure of a DC microgrid 


\subsection{Control strategies of DC microgrids}

Effective control strategies are crucial to stable and efficient operation of the DC microgrids. Control strategies for DC microgrids consist of centralized, decentralized, distributed and hierarchical controls [18]. Decentralized control is able to optimize resource utilization and retain system reliability based on local measurement without communication [19]. It is more suitable for a DC microgrid with small capacity [20]. Droop control is a typical representative of decentralized control methods. The control method based on the droop characteristic of a converter has been proved effective in merging multiple sources and storages. Since control methods have obvious impact on the transient behavior of DC microgrids, they significantly affect protection aspects [7]. In order to improve the transient characteristics of DC microgrids subsequent to fault, control strategies should be constantly developed. For example, a new droop control algorithm proposed in [21] makes it possible to control charge/discharge prioritization, thus the batteries are protected from transient cycling. A dynamic droop method in [22] proposed for a hybrid energy storage system (HESS) has been proved more effective than the preceding droop control. Both of the new control methods have contributed to the DC microgrids stable operation.

\section{DC protection systems}

\subsection{Fault characteristics}

According to its fault character, DC microgrids fault types are pole-to-pole fault and pole-to-ground fault. The pole-to-ground faults are the most common in industrial systems [23]. Generally, the fault impedance of pole-topole faults is low. However, the fault impedance of pole-toground faults can be either low or high. On the other hand, the fault types can be bus fault and feeder fault based on the fault location. As mentioned, the electronic equipment is vulnerable and the tolerance of the over current is finite. The fault would be much severer when the fault location is closer to the energy sources; therefore the bus fault is critical for the whole system. Faults inside VSCs and batteries may cause a pole-to-pole short-circuit fault and these are terminal faults that generally cannot be quickly cleared. In these cases, the devices have to be replaced and using fuses could be a proper choice.

The typical fault response of a converter interfaced DC network is presented in detail in [4]. In case of a DC shortcircuit fault, the IGBTs are immediately blocked for selfprotection, leaving reverse diodes exposed to overcurrent. In the meantime, the charged filter capacitors play the role

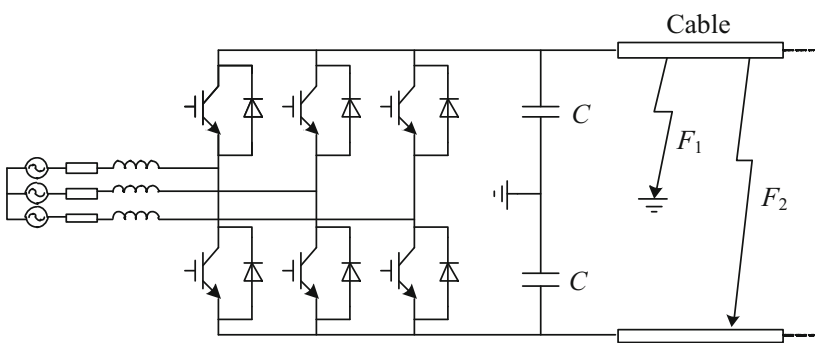

Fig. 2 Equivalent circuit of the faulted network

of high fault-level sources, the typical fault current profile can be depicted by the equivalent circuit illustrated in Fig. 2 regardless of where the DC-cable short-circuit occurs. Comprehensive and systematical analyses were done in [24] using the Laplace method, where the natural responses of the equivalent circuit were defined in two separate phases. The fault characteristics can be obtained from these analyses, and help to define protection operation time and assess the effect of any proposed protection schemes.

The pole-to-pole fault is the most typical type in DC microgrids. The pole-to-pole fault response can be depicted in three stages: capacitor discharge stage, diode freewheel stage and grid-side current feeding stage. The equivalent circuit is shown in Fig. 3.

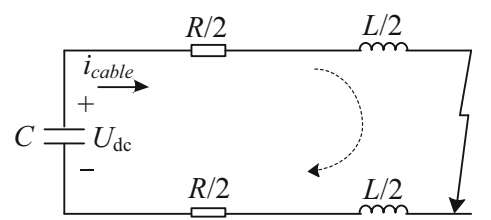

(a)

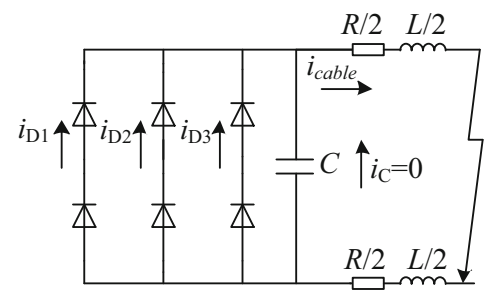

(b)

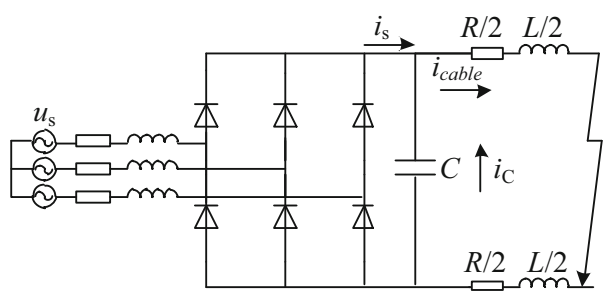

(c)

Fig. 3 Equivalent circuit for pole-to-pole short-circuit fault 
1) Capacitor discharge stage. In this stage, the DC-link capacitor discharges immediately after the fault, shown in Fig. 3a, and the expression could be given by:

$L C \frac{\mathrm{d}^{2} u_{\mathrm{dc}}}{\mathrm{d} t^{2}}+R C \frac{\mathrm{d} u_{\mathrm{dc}}}{\mathrm{d} t}+u_{\mathrm{dc}}=0$

Under the condition of $R<2 \sqrt{L / C}$, while assuming the fault occurs at time $t_{0}$, the initial voltage and current to be $u_{\mathrm{dc}}\left(t_{0}\right)=U_{0}, i_{\text {cable }}\left(t_{0}\right)=I_{0}$, the solution of (1) is:

$u_{\mathrm{dc}}=\frac{U_{0} \omega_{0}}{\omega} \mathrm{e}^{-\delta t} \sin (\omega t+\beta)-\frac{I_{0}}{\omega C} \mathrm{e}^{-\delta t} \sin \omega t$

$i_{\text {cable }}=C \frac{\mathrm{d} u_{c}}{\mathrm{~d} t}=-\frac{I_{0} \omega_{0}}{\omega} \mathrm{e}^{-\delta t} \sin (\omega t-\beta)+\frac{U_{0}}{\omega L} \mathrm{e}^{-\delta t} \sin \omega t$

where

$\delta=R /(2 L) ; \omega^{2}=1 /(L C)-[R /(2 L)]^{2} ; \omega_{0}=\sqrt{\delta^{2}+\omega^{2}} ;$ $\beta=\arctan (\omega / \delta)$.

2) Diode freewheel stage. This stage shown in Fig. $3 b$ is initiated when the DC-link voltage reaches zero. Assuming the stage happens at time $t_{1}$, the initial value of the current is $i_{\text {cable }}\left(t_{1}\right)=I_{1}$. The expression of the cable current is given by:

$i_{\text {cable }}=I_{1} \mathrm{e}^{-\frac{R}{L}\left(t-t_{1}\right)}$

3) Grid-side current feeding stage. At that stage, the equivalent circuit performs as an uncontrollable rectification depicted in Fig. 3c. Without fault clearance, although the fault current is reduced significantly at that time, it will exist for a long time and there is no zerocrossing point.

The typical pole-to-pole fault characteristics are shown in Fig. 4, the fault response can be depicted in three stages: capacitor discharge stage, diode freewheel stage and gridside current feeding stage. Assuming the fault happens at $t_{0}$, the capacitor quickly begins to discharge and the fault current reaches its peak in a few milliseconds until the capacitor voltage drops to zero. After that, the cable inductance begins to drive the current around the freewheel diodes path as illustrated in the period $t_{1}$ to $t_{2}$. At that moment, the current through the diodes is abrupt so that the didoes would be rapidly damaged. After a certain attenuation, the DC side of the fault current and $\mathrm{AC}$ side current are nearly of the same magnitude. Consequently, the AC side feeds the fault point, as described for the time after $t_{2}$. Pole-to-ground fault has been analyzed in detail in [25]. Compared with the pole-to-pole fault, the typical pole-toground fault does not have the diode freewheel stage, although the rest of the features are similar.

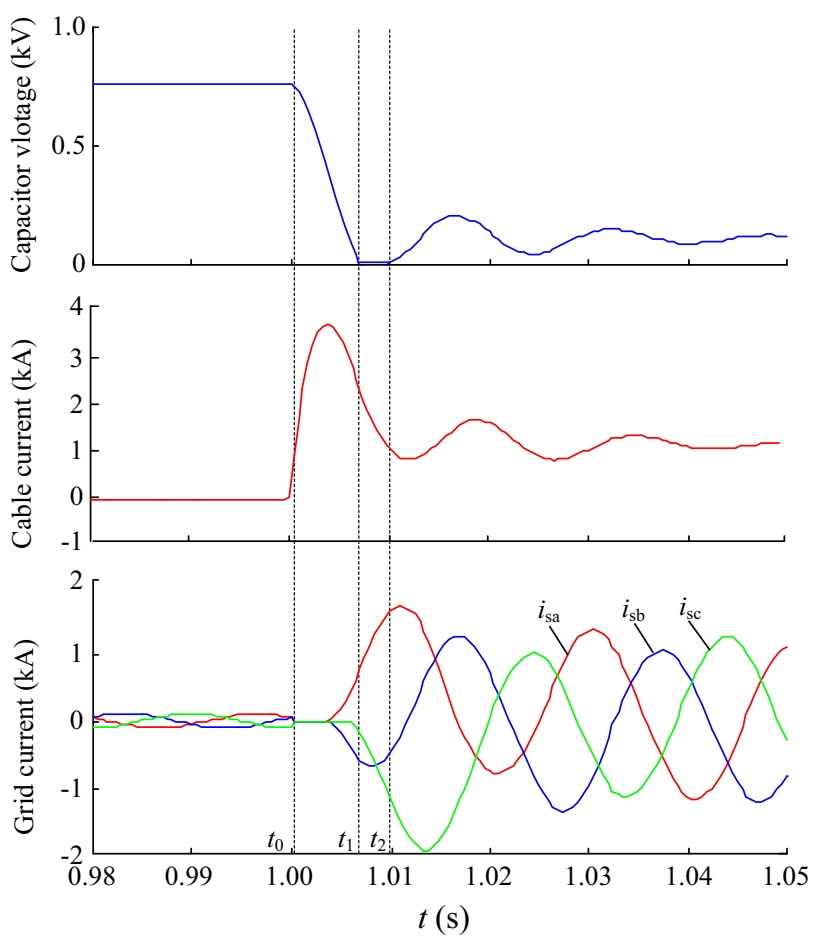

Fig. 4 Typical pole-to-pole fault characteristics

\subsection{Protection devices}

At present, the commercially available protection devices for DC microgrids are fuses and circuit breakers [11]. Interruption of the current leads to the creation of an arc that cannot be easily extinguished in a DC system without the current crossing through zero. That's still a challenge for applying the DC power system technologies. Fortunately, those difficulties have to be gradually overcome.

Fuses are the most traditional protection devices through melting down the fuse link in the circuit. Fuses are applicable for both AC and DC systems. Different from DC systems, the ratings in AC systems are determined in terms of RMS values. However, given the restriction on time of protection and the time constant of the fault current, fuses are carefully chose based on application.

Circuit breakers are the key equipment in DC systems; however these current devices cannot totally and perfectly satisfy the protection requirements. Traditional moldedcase circuit breakers (MCCB) are the most common protection devices in current $\mathrm{DC}$ systems. The tripping device of the MCCB could either be thermal-magnetic or electronic so that the ratings are quite different. The magnetic tripping devices detect the instantaneous values while the thermal tripping devices sense the RMS values of the current. In order to achieve sufficient voltage blocking capacity, the contactors could be connected in a series in both cases [26]. However, the discharge current of the filter 
capacitor after the short circuit are of high magnitude which lasts for a very short time. Therefore, the case may exist that the current force is unable to open the contacts of the MCCBs.

In order to break down the limitation of the usage of fuses and MCCBs, power electronic based protection devices were proposed and developed. These commonly refer to solid-state circuit breakers (SSCB) [27, 28] and hybrid circuit breakers [29, 30]. Semiconductor devices such as insulated-gate bipolar transistors, insulated-gate commutated thyristors and gate turn-off thyristors are the predominate components that determine the characteristics of these novel protection devices. Although these devices have more power losses, they could be a feasible method to meet the strict protection requirements. The comparisons of these typical electronic-based circuit breakers are listed in Table 1 [31].

Reference [32] investigated the technical parameters such as reliability, power losses and relative investment costs of different DC breakers and concluded that the solidstate circuit breaker shows the best overall performance. Hybrid mechanical and solid state circuit breakers have not been available in practice. Mechanical passive or active resonance circuit breakers are specifically applied in CSC HVDC [33]. Therefore, SSCB is available and technically feasible for MVDC applications, the SSCB and hybrid solid-state DC circuit breakers are appropriate for the DC microgrids. The relatively high conducting loss remains a major drawback of SSCB, thus selection of SSCB semiconductors are an important design factor [34]. Since 2011,
SiC JFET/SIT were identified and implemented in building LV and MV SSCBs and the conducting losses were significantly reduced [35-39]. The hybrid solid-state DC circuit breaker with mechanical disconnector provides an ultra-fast and efficient protection solution [40]. With the improved topology, a $2 \mathrm{~ms}, 10 \mathrm{kV}$ class hybrid DC circuit breaker prototype based on a single $15 \mathrm{kV} \mathrm{SiC} \mathrm{ETO} \mathrm{device}$ is presented in [41]. Meanwhile, the development of semiconductor technology pushes hybrid DC circuit breakers to a new level. As a result, the developments of DCCBs for DC microgrids primarily focus on the topology structure and the power electronic device selection.

\subsection{Grounding options}

Grounding is a critical issue for DC microgrids protection. Different grounding options come with different fault characteristics and influence the configuration and setting of the protection. The purpose of grounding designs is to facilitate the ground fault detection, minimize the stray current and to ensure the personnel and equipment safety [42]. As proposed, DC microgrids could be grounded with either high resistance or low resistance, even ungrounded [11]. However, none of these grounding alternatives have been widely accepted.

The ungrounded mode has been highly recommended especially in LV applications [43, 44]. In that case, the common-mode voltage could not be high enough to pose a threat to personnel and equipment safety. Meanwhile the system could operate continuously when a single phase-to-

Table 1 Comparisons of typical protection devices

\begin{tabular}{|c|c|c|c|c|}
\hline Parameter & Full solid state $\mathrm{CB}$ & $\begin{array}{l}\text { Hybrid solid state } \\
\text { CB with mechanical } \\
\text { disconnector }\end{array}$ & $\begin{array}{l}\text { Hybrid mechanical } \\
\text { and solid state } \mathrm{CB}\end{array}$ & $\begin{array}{l}\text { Mechanical passive or active resonance } \\
\text { CB }\end{array}$ \\
\hline Interruption time & $<1 \mathrm{~ms}$ & $<2 \mathrm{~ms}$ & $<5-30 \mathrm{~ms}$ & $<60 \mathrm{~ms}$ \\
\hline $\begin{array}{c}\text { Maximal rated } \\
\text { voltage } U_{n}\end{array}$ & $<800 \mathrm{kV}$ & $\begin{array}{l}120 \mathrm{kV} \text { verified by } \\
\text { test (up to } 320 \mathrm{kV} \\
\text { achievable) }\end{array}$ & $\begin{array}{l}\text { AC circuit breakers } \\
>500 \mathrm{kV} \text { ultra- } \\
\text { fast-switches } \\
<12 \mathrm{kV}\end{array}$ & $<550 \mathrm{kV}$ available \\
\hline $\begin{array}{l}\text { Maximal DC } \\
\text { breaking } \\
\text { current } I_{n}\end{array}$ & $<5 \mathrm{kA}$ expected & $\begin{array}{l}9 \mathrm{kA} \text { experimentally } \\
\text { proven (up to } \\
16 \mathrm{kA} \text { expected) }\end{array}$ & $\begin{array}{l}\sim 6-12 \mathrm{kA} \\
\quad(\text { estimated })\end{array}$ & $\begin{array}{l}\text { Up to } 4 \mathrm{kA} \text { proven in operation (up to } \\
8 \mathrm{kA} \text { possible with active resonance) }\end{array}$ \\
\hline $\begin{array}{l}\text { Expected power } \\
\text { loss in } \\
\text { comparison to a } \\
\text { VSC converter } \\
\text { station }\end{array}$ & $\begin{array}{l}<30 \% \text { (large forward voltage due } \\
\text { to serial connection of solid } \\
\text { state devices) }\end{array}$ & $\begin{array}{l}<1 \% \text { (only few } \\
\text { IGBTs in series in } \\
\text { the main path) }\end{array}$ & $\begin{array}{l}<0.001 \% \text { (metal } \\
\text { contacts) }\end{array}$ & $<0.001 \%$ (metal contacts) \\
\hline $\begin{array}{l}\text { Further } \\
\text { development } \\
\text { steps }\end{array}$ & $\begin{array}{l}\text { Development in solid state device } \\
\text { technology to reduce on-state } \\
\text { forward voltage and number of } \\
\text { modules in series }\end{array}$ & $\begin{array}{l}\text { Field experience } \\
\text { with prototype in } \\
\text { a test grid; } \\
\text { reduction of IGBT } \\
\text { costs }\end{array}$ & $\begin{array}{l}\text { Development of } \\
\text { ultra-fast- } \\
\text { mechanical drives } \\
\text { to reduce } \\
\text { commutation time }\end{array}$ & $\begin{array}{l}\text { Optimization of DC arc chamber for } \\
\text { passive resonance to achieve higher } \\
\text { current rating and to minimize time } \\
\text { for current zero creation }\end{array}$ \\
\hline
\end{tabular}


ground fault occurs. However, a possible second ground fault at another pole may result in a line-to-line fault and do severe damage to the whole system [45].

Solid grounding has rarely been adopted because of the corrosion caused by stray current [42]. Compared with low resistance grounding, high resistance grounding limits the ground fault current so that the system could keep operating during a fault, but the detection and location of the fault becomes much more difficult. Moreover, the point of the system selected to be grounded could be the midpoint, the positive or the negative pole of the common DC link [46]. For that matter, [47] suggests midpoint grounding to minimize the ground potential and enhance the whole system's safety. Similar to an AC power system, the IEC 60364 standard [48] determines three grounding strategies TN, IT and TT which are shown in Fig. 5. TN systems are typical low impedance grounded, the detection of the line fault is easy to implement, but the touch voltage may be incredibly high. Different from TN systems, IT systems require high impedance, the fault current is low and increases the detection difficulty. On the other hand, TT systems have multiple grounding points and the fault does not migrate [44].

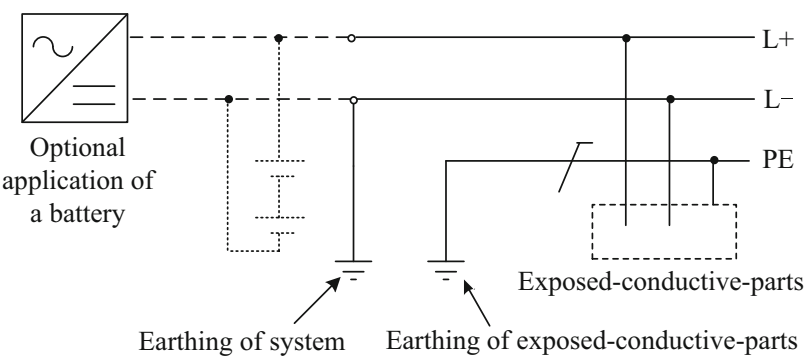

(a) TN system

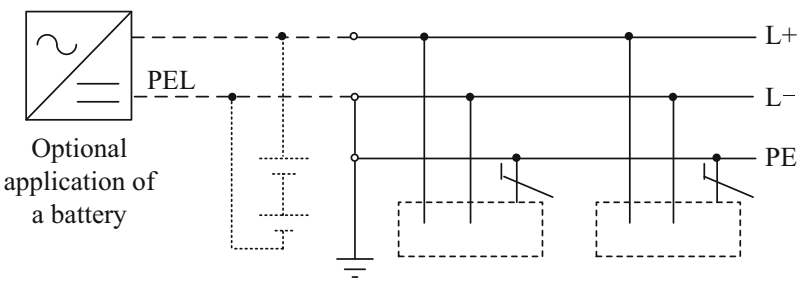

Earthing of system Exposed-conductive-parts

(b) TT system

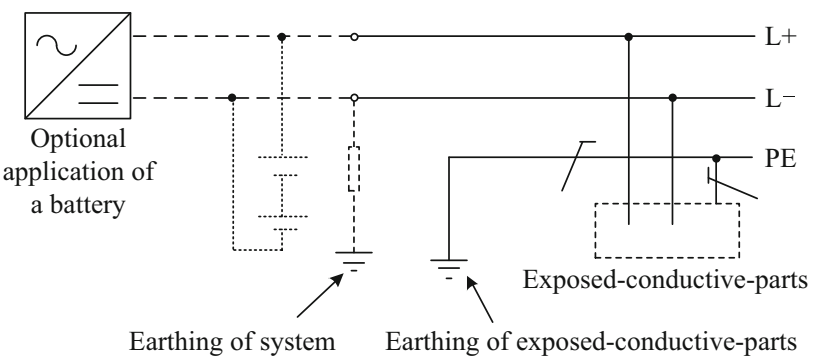

(c) IT system

Fig. 5 DC microgrids grounding

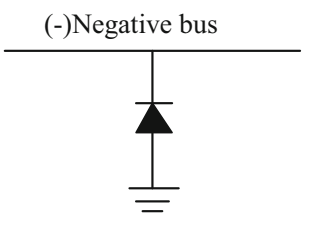

Fig. 6 Block diagram of diode grounding system

In addition to these methods aforementioned, an automatic grounding method has been presented in [42]. Diode grounding depicted in Fig. 6 consists of a connection of the DC system negative pole with the ground through a diode. In that case, the system will be automatically transformed to ungrounded mode when the ground faults happen at the negative pole. However, in this type of system, a periodic maintenance is required to protect against the possibility of corrosion [49].

\subsection{Simulation software}

The fault analysis and protection coordination simulation is extremely important for protection design and implementation. As for the matter of the electro-magnetic transient (EMT) process simulation of DC microgrids, several applicable simulation softwares are list in Table 2 [50-52]. Among them, PSCAD/EMTDC is designed initially for a DC system EMT analysis. Meanwhile PSCAD is also widely used in modeling HVAC and FACTS devices. As the power systems become more and more complex with a large quantity of electronic devices, real time simulations are increasingly important in modeling. Real time simulations such as RTDS primarily include control, protection and investigation of operational problems [53].

\section{Protection principle and schemes}

Similar to AC systems, the protection schemes designed for DC systems are divided into non-unit and unit protection techniques. All the desirable characteristics like reliability, selectivity, speed, performance, economics and simplicity have to be taken into consideration when designing a protection system [26]. In this section, the current proposed protection schemes for DC systems are summarized.

\subsection{Non-unit protection}

Non-unit protection is not able to protect a distinct zone of the power system and operates directly when the threshold is exceeded. Meanwhile, non-unit protection schemes have inherent advantages for coordinating the whole protection system [4]. Non-unit protection realizes 
Table 2 Comparison of several applicable simulation softwares

\begin{tabular}{|c|c|c|}
\hline Software & Study type & Features \\
\hline EMTP & EMT analysis & $\begin{array}{l}\text { Calculation precision is identified by IEEE and CIGRE; } \\
\text { abundant models }\end{array}$ \\
\hline $\begin{array}{l}\text { PSCAD/ } \\
\text { EMTDC }\end{array}$ & EMT analysis, especially feasible for DC system & Precious DC simulation components and models \\
\hline PSAPAC & Steady and transient state analysis & Comprehensive function in power system simulation \\
\hline BPA & Load flow and transient stability analysis & Feasible for large-scale AC/DC power system \\
\hline PSASP & $\begin{array}{l}\text { Steady state, fault process, and electromechanical transient } \\
\text { stability analysis }\end{array}$ & Mainly used in electromechanical transient stability analysis \\
\hline $\mathrm{PSS} / \mathrm{E}$ & Steady and dynamic state analysis & $\begin{array}{l}\text { Especially feasible for electromechanical transient stability } \\
\text { analysis }\end{array}$ \\
\hline DigSILENT & Almost all power system analysis function & Steady and dynamic state analysis; harmonic analysis \\
\hline RT_LAB & Large-scale power system transient stability analysis & $\begin{array}{l}\text { Feasible for FACTS and HVDC control component design; } \\
\text { real time simulation }\end{array}$ \\
\hline RTDS & Real time simulations; protection testing; control system testing & $\begin{array}{l}\text { Feasible for real time simulations of small-scale power } \\
\text { system }\end{array}$ \\
\hline
\end{tabular}

fault discrimination in a DC microgrid system by analyzing the current, voltage, $\mathrm{d} i / \mathrm{d} t, \mathrm{~d} v / \mathrm{d} t$ and the impedance response in a range of the fault. A protection system designed in [3] combined the usage of the current, voltage and $\mathrm{d} i / \mathrm{d} t$ information to realize fault detection based on a case study. On the other hand, this paper analyzed the coordination of non-unit protection in a new perspective. A two-section current protection principle and reverse current protection principle were proposed in [54], in which the protection schemes sufficiently utilized the fault current direction information. Reference [55] presented a protection scheme based on the fault current natural characteristics and its first and second order derivatives. Various faults are easily discriminated with the derivatives of the currents. The approach for a multiterminal DC distribution system based on overcurrent protection was outlined in [56]. Though proved effective, this approach is unable to acutely sense the fault in the case where the DC line is short and the system is ungrounded. As for the loop network, [57] proposed protection schemes with instantaneous current $\mathrm{d} i / \mathrm{d} t$ information. However, the selectivity of nonunit protection methods was on the basis of complex setting values and proper time delays. Given that, current limiting methods were presented to release the time coordination tension [58-60].

A resistive superconductive fault current limiter (SFCL) that could quickly respond to the short circuit fault was applied within [61]. A resistance SFCL consists of a shunt resistance and a superconducting cable as shown in Fig. 7. The parallel shunt resistance is used for limiting the overvoltage. The resistance SFCL can operate in the superconducting mode or in the normal resistive mode. When the critical temperature is exceeded, the resistance

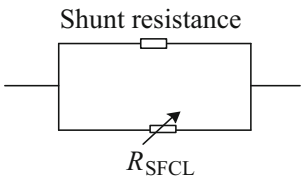

Fig. 7 Structure of the resistance SFCL

SFCL enters the normal state to limit the fault current. In that case, a novel transient current protection method based on the peak value of the current and the transient time for the fault current to reach its peak was put forward.

The effect of SFCL is shown in Fig. 8. In comparison with Fig. 1, the result is obtained with the same simulation parameters except for the installation of the SFCL. As illustrated in those two figures, the DC cable peak current is reduced from $3.7 \mathrm{kA}$ down to $0.45 \mathrm{kA}$, meanwhile the decrease of the capacitor voltage is also limited. The diodes will not suffer the high magnitude fault current as the DC voltage never drops to zero. The currents of the DC line, AC side and through the diodes are obviously limited, and the protection scheme has more time to clear the fault.

In order to realize the ability to distinguish the different fault zones and facilitate the non-unit protection, recent researches advised to install current limiting reactors that could increase the electrical distance [62, 63]. A small reactor was installed at each head of the line to set protection boundaries, thus adjacent lines are easily discriminated. In [62], the system simply adopted the over current and low voltage protection principle, but there was no need to utilize time delay to guarantee the selectivity. In fact, this method that uses current limiting reactors to divide the grid into different zones is borrowed from the protection scheme in HVDC grids. In the DC system, this approach 

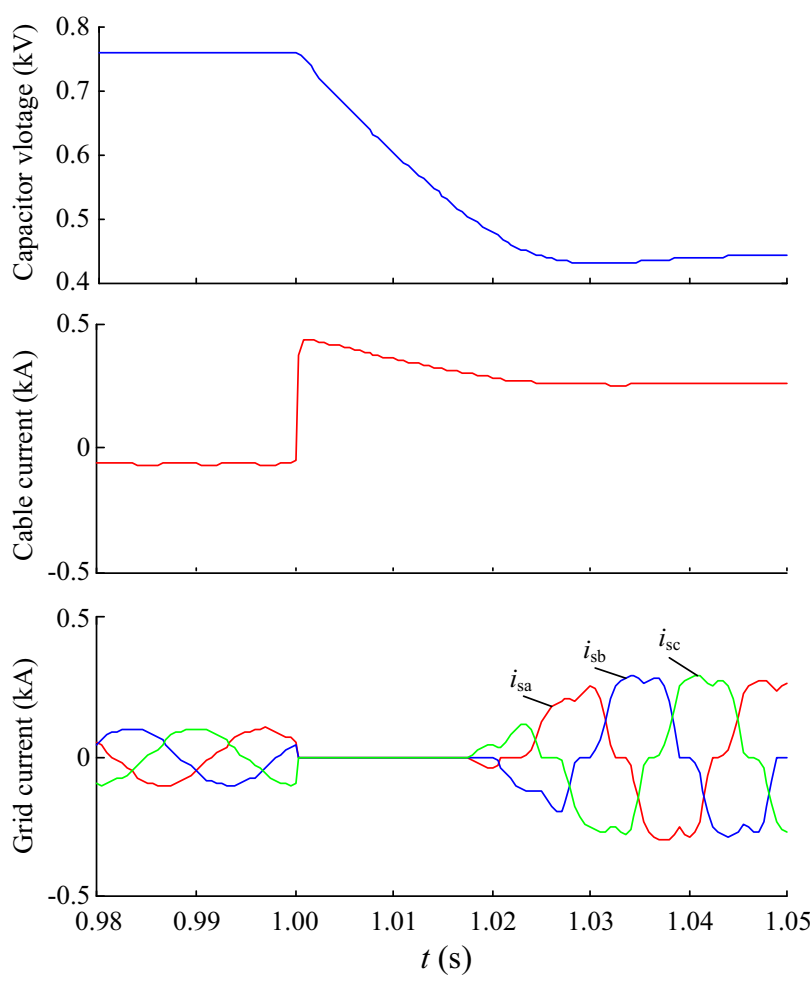

Fig. 8 Fault characteristics of a pole-to-pole fault with the SFCL

makes it possible to realize the whole system protection simply with applying non-unit protection methods.

In addition, an artificial neural network (ANN) protection method has been widely used in AC systems [64-66]. The intelligent-based method can realize fault detection and location without requiring complex mathematical equation derivations. The ANN protection is applicable in DC systems since the sample data could be directly fed to the ANN [67]. High frequency components of the fault current were selected to feed the ANN in [68] for accurate fault detection and location in multiple-HVDCs. The proposed method is robust and immune to fault resistance. ANN-based protection schemes, which are capable of DC fault detection and classification, have broad application prospects in DC microgrids. However, the noise and incorrect sampling for sample data remain a problem [69].

\subsection{Unit protection}

Because of the additional cost of the crucial communication and relay devices, the implementation of the unit protection method is closely restricted. But the development of the smart grid and microgrid will call for an increased investment of sensors and communication infrastructures within the distribution systems to achieve advanced automatic network monitoring and management [70, 71]. Apparently the deployment of these devices will provide the opportunity to promote the application of the unit protection schemes. Research in [4] has investigated the capability of non-unit protection schemes to realize effective fault discrimination and the result reflected the limitations of these methods. Unit protection supports a clear zone and never responds to an external circuit fault. In comparison with non-unit protection, unit protection does not have backup protection to the adjacent elements in the system [72], thus it is common that the non-unit protection is deployed alongside the unit protection to act as a backup protection.

The comparisons in [4] have clearly demonstrated the advantages of unit protection. Unit protection can be classified as data-based and event-based protection schemes [73-78]. As described in [75], electric variables measured at different points in a system are sent to the interconnected unit to identify the fault in the data-based protection method, while in the event-based protection method the measurements during the fault are analyzed and judged locally and then the fault judgment will be sent to other interconnected protection units. According to [75], the event-based protection method does not call for highspeed communication and synchronization and it transfers less data than the data-based protection method.

\subsubsection{Data-based protection scheme}

A current differential protection scheme based on the case of a loop-type DC bus was proposed in [23], the scheme simply uses the current difference to achieve fault discrimination. Similarly, in addition to the current differential protection scheme, the under-voltage protection scheme was deployed as a back-up [79]. To realize protection coordination and fault location, a further study was done in [15]. The concept of an intelligent electric device (IED) that aggregates the function of the fault detection and isolation was put forward.

As shown in Fig. 9, three CBs controlled by an IED are installed at each node; the fault can be detected by a differential current and can be isolated as quickly as possible. Meanwhile, an IED would send specific signals to adjacent IEDs to open their adjacent CBs on the link in case of a CB open failure. Therefore, the affected parts are isolated and the remaining parts can continue to operate. Fault current data was transferred between the adjacent relays based on the generic object oriented substation events (GOOSE) message to identify the fault zone in [73]. A high-speed fault detection and isolation method that utilizes the natural characteristics of the DC difference was presented in [80], and made it possible to use the high-speed circuit breaking technologies. At the same time, the reference pointed out the synchronization problem of current measurement in the case of high $\mathrm{d} i / \mathrm{d} t$ in the DC system. As the devices in the 


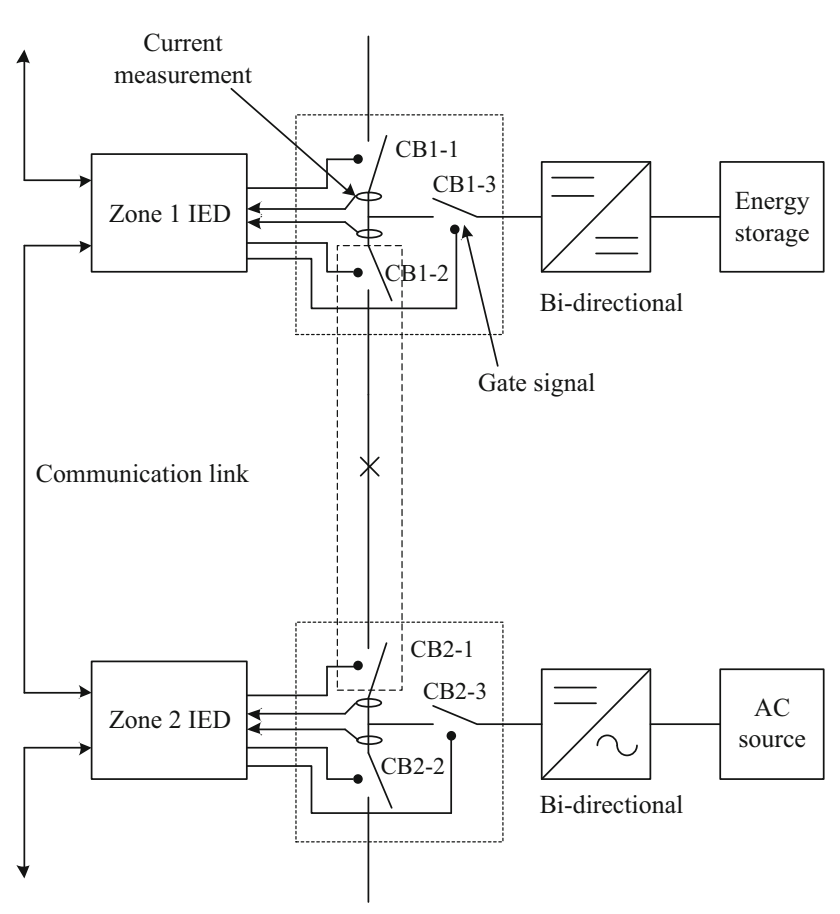

Fig. 9 Protection scheme with IED. Each IED controls node/link $\mathrm{CBs}$ and communication links

communication links are synchronized through GPS time stamping [81], the accuracy of the time synchronization would be $1 \mu$ s and would overcome the challenge of the current differential protection method.

\subsubsection{Event-based protection scheme}

Different from data-based protection schemes, the event-based protection scheme enables each power unit to identify the type of a fault automatically [75]. Similar to some non-unit protection, artificial inductive line impedances (AILI) are implemented in each of the feeders to facilitate the fault discrimination with the value of $\mathrm{d} i$ / $\mathrm{d} t$. The strategy of the mentioned event-based protection is shown in Fig. 10, the initial judgment as to whether it is bus fault, interconnected fault or adjacent feeder or bus fault is made locally, then this event information will be transferred between the interconnected units through highlevel data communication to identify the fault more comprehensively and systematically. Subsequently, the final decision will be made and the protection devices will quickly react. However, given the severity of a bus fault, a decision will be made immediately without the step of reconfirmation through communication [82]. The proposed scheme is able to accurately achieve fault identification. The fault can be isolated within $30 \mathrm{~ms}$, followed by the system restoration. Meanwhile the load voltage drop is limited to $3 \%$.

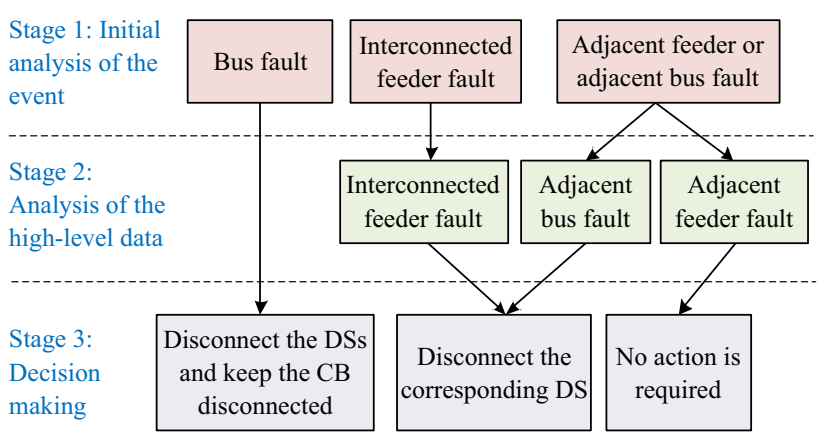

Fig. 10 Event-based protection strategy

Despite its remarkable characteristics, the unit protection scheme might work in the case of communication delay or failure. Meanwhile, fault detection and isolation will become more challenging and the whole system may be exposed to danger [83]. To guarantee security, non-unit protection is usually deployed alongside the unit protection to act as a backup protection. Furthermore, [78] presented a handshake method to divide the system into three possible zones to facilitate isolation of any possible bus faults. Although the method has the drawback of completely shutting down the whole system after the fault, it is still effective as a backup protection scheme.

\subsection{Other problem of protection}

\subsubsection{Ground fault monitoring technique}

In addition to the protection schemes, ground fault monitoring techniques for the DC microgrid are also important. Detecting a high-resistance grounding fault proves a tough and challenging task for DC system safety. Traditionally, the methods of AC injection and DC leakage are widely used [84]. The method of AC injection monitors the ground fault through injecting a low frequency sine wave signal into the DC system, while the method of DC leakage directly inspects the ground fault with a DC leakage current. Reference [84] proposed a novel method of injecting different frequency signals. This method maintains both the advantages of high precision of the traditional AC injection method and it can be protected from the influence of the distributed capacitor in the DC system. A ground fault monitoring technique for an extralow voltage direct current (ELVDC, up to a $60 \mathrm{~V} \mathrm{DC}$ ) distribution system was presented in [85]. A built environment equipotential property was applied in this technique. It is a good solution for ground fault detection when the DC leakage current is at a low level and not detectable. Reference [44] designed a probe unit to detect and locate the ground fault for unground a DC traction system. Although the proposed method realized fast detection and 
accurate location of the ground fault, it increased the cost with the need for additional equipment. A novel high-resistance ground fault monitoring method for DC railway traction systems was put forward in [86]. The voltage and current of two adjacent substations are applied in calculating the ground fault. The resistance effect was wiped out with the help of communications. At present, effective ground fault monitoring techniques for DC microgrids are still in demand.

\subsubsection{Control scheme effect on protection}

As mentioned in Section 2.2, control strategies have a strong effect on protection aspects. Reference [87] investigated the impact of power flow strategies on fault response in MTDC systems. A single converter voltage control (SVC) method and distributed voltage control (DVC) method were employed respectively to compare the fault dynamic characteristics. The fault response included two aspects: the fast fault isolation and the post-fault control of system recovery. Only overcurrent protection was implemented in that paper, thus the fault identification and fast fault isolation were independent from the control method. However, the post-fault operation was affected to some degree. When the SVC was applied, once the single VSC controlling the DC voltage was blocked after the fault, the system would never resume normal operation. However, in the case of the DVC, the system could maintain the voltage control capability and come back to the set voltage operation state. As a result, the DVC strategy strengthened the fault ride-through its ability to some extent.

The overcurrent protection is immune to the voltage control method, so that the protection scheme, by analyzing the voltage or $\mathrm{d} v / \mathrm{d} t$ such as undervoltage protection, would be affected. In addition, when the constant current control method is applied, the fault current could be suppressed to about 0.1 p.u. [88]. Therefore, the current protection schemes have to adjust their setting values.

\subsubsection{Operation criterions and setting rules}

In Sections 4.1 and 4.2, the non-unit and unit protection are depicted in detail. Furthermore, the principle, operation criterions and setting rules are summarized in Table 3.

\section{Research prospect}

In this paper, the basic protection schemes and grounding methods have been discussed within the framework of the current available protection devices. To solve the protection issues and to promote the development of the DC microgrid, it is necessary to point out the key lines of future research. The future protection research directions lie in the development of novel protection devices based on electronic technology, which could provide loose protection constraints and the improvement of the protection schemes suitable for the DC microgrids.

\subsection{Novel protection devices}

As for the isolation of the DC faults in the DC grid, various types of new structures of circuit breakers have gained a great deal of attention. To overcome the current commutation difficulty of hybrid direct current circuit breakers that consist of a mechanical and static DCCB branch, a current commutation drive circuit (CCDC) that has low cost, low operation losses and free maintenance is proposed [30]. The press-pack IGBT mechanical design of SSCB has been solved and makes it possible to provide practical application of SSCBs based on series-connected IGBTs [90]. Reference [91] presented a new SSCB with the ability of quickly isolating a fault with no delay in the breaking operation. The researches on DCCB will continue and finally bring a product that meets the technical and economic requirements.

\subsection{Grounding and protection scheme}

A grounding method has not been determined for DC microgrids and this will continue to be an important research topic. The fast acting grounding devices to limit fault current on the basis of solid-state technology need more attention as well. Moreover, novel protection schemes based on fault characteristics are still required to realize fast and accurate fault detection and isolation. Although the aforementioned protection methods all behave well to some degree, the protection coordination of upstream and downstream devices is envisioned as a further study topic in the future. Therefore, all types of protection devices need to be coordinated and integrated into an overall protection system.

\subsection{Coordinated strategy of control and protection}

Since a microgrid integrates multiple distributed generations, energy storages, energy conversion devices and loads, the coordination control strategy of those components is of great importance [92]. To ensure efficient, safe and economical operation of the system, it is impossible to split control and the protection in future considerations. An effective control strategy can bring the system back to normal after a small disturbance. Even under a short-circuit fault condition, an effective strategy can reduce the severity of the fault to some degree by controlling the fault 
Table 3 A summary of protection schemes of DC microgrids

\begin{tabular}{|c|c|c|c|c|c|}
\hline \multirow{2}{*}{$\begin{array}{l}\text { Protection } \\
\text { scheme }\end{array}$} & \multicolumn{3}{|l|}{ Non-unit protection } & \multicolumn{2}{|l|}{ Unit protection } \\
\hline & Current based & Voltage based & $\begin{array}{l}\text { Hybrid electrical } \\
\text { quantities based }\end{array}$ & Differential & Event based \\
\hline Principle & $\begin{array}{l}\text { Detect the fault } \\
\text { through current, } \\
\mathrm{d} i / \mathrm{d} t \text {, and even } \\
\mathrm{d}^{2} i / \mathrm{d} t^{2}\end{array}$ & $\begin{array}{l}\text { Identify the fault } \\
\text { through voltage, } \\
\mathrm{d} u / \mathrm{d} t\end{array}$ & $\begin{array}{l}\text { Detect the fault through } \\
\text { hybrid electrical } \\
\text { quantities }\end{array}$ & $\begin{array}{l}\text { Distinguish the internal } \\
\text { and external fault with } \\
\text { current differential }\end{array}$ & $\begin{array}{l}\text { Judge the fault } \\
\text { type locally and } \\
\text { interconnect } \\
\text { with other units } \\
\text { to make fault } \\
\text { isolation } \\
\text { decision }\end{array}$ \\
\hline Communication & No & No & No & Yes & Yes \\
\hline $\begin{array}{l}\text { Operation } \\
\text { criterions }\end{array}$ & $\begin{array}{l}i>i_{t h}, \Delta i>i_{t h}^{\prime} \\
\Delta^{2} i>i_{t h}^{\prime \prime}\end{array}$ & $u>u_{t h}, \Delta u>u_{t h}^{\prime}$ & $\begin{array}{c}i>i_{t h}, \Delta i>i_{t h}^{\prime}, \Delta^{2} i>i_{t h}^{\prime \prime} \\
u>u_{t h}, \Delta u>u_{t h}^{\prime}, x<x_{t h}\end{array}$ & $i_{\text {diff }}=\left|i_{\text {in }}+i_{\text {out }}\right|>i_{\text {d_th }}$ & $\begin{array}{l}\text { Fault event is } \\
\text { determined by } \\
\text { communication } \\
\text { with other } \\
\text { interconnected } \\
\text { units }\end{array}$ \\
\hline Setting rules & $\begin{array}{l}\text { Threshold depends on } \\
\text { the current related } \\
\text { values when direct } \\
\text { short circuit fault } \\
\text { occurs at the end of } \\
\text { the protected scope }\end{array}$ & $\begin{array}{l}\text { Threshold depends on } \\
\text { the voltage related } \\
\text { values when direct } \\
\text { short circuit fault } \\
\text { occurs at the end of } \\
\text { the protected scope }\end{array}$ & $\begin{array}{l}\text { Threshold depends on the } \\
\text { hybrid electrical } \\
\text { quantities related or } \\
\text { fault location values } \\
\text { when direct short } \\
\text { circuit fault occurs at } \\
\text { the end of the protected } \\
\text { scope }\end{array}$ & $\begin{array}{l}\text { Threshold is mainly based } \\
\text { on the overcurrent } \\
\text { value of the power } \\
\text { electronic devices, } \\
\text { measurement errors, } \\
\text { and induced noise and/ } \\
\text { or transients of external } \\
\text { faults }[79,89]\end{array}$ & $\begin{array}{l}\text { Fault type } \\
\text { judgment } \\
\text { threshold } \\
\text { setting rules } \\
\text { similar to non- } \\
\text { unit protection } \\
\text { schemes }\end{array}$ \\
\hline Comments & $\begin{array}{l}\text { Appropriate threshold } \\
\text { is need; sensitive to } \\
\text { fault resistance }\end{array}$ & $\begin{array}{l}\text { Appropriate threshold } \\
\text { is need; sensitive to } \\
\text { fault resistance }\end{array}$ & $\begin{array}{l}\text { Setting rules is complex } \\
\text { to some degree; } \\
\text { sensitive to fault } \\
\text { resistance }\end{array}$ & $\begin{array}{l}\text { Only the magnitudes of } \\
\text { currents are needed to } \\
\text { compare; insensitive to } \\
\text { high } \mathrm{d} i / \mathrm{d} t \text { and fault } \\
\text { resistance }\end{array}$ & $\begin{array}{l}\text { Achieving fault } \\
\text { identification } \\
\text { accurately; } \\
\text { isolating fault } \\
\text { within } 30 \mathrm{~ms}\end{array}$ \\
\hline
\end{tabular}

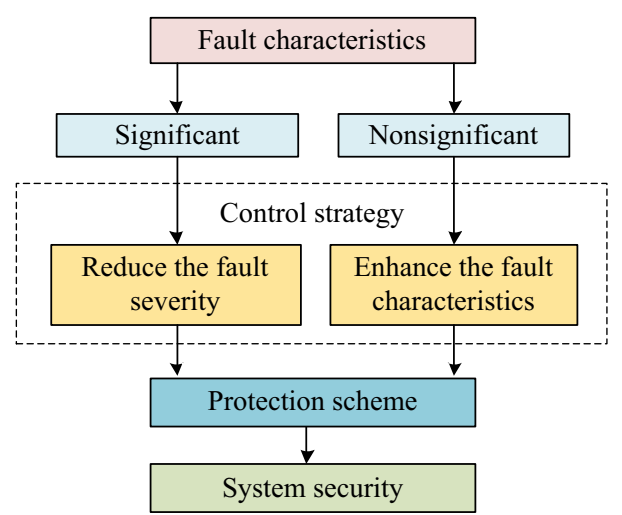

Fig. 11 Coordinated strategy of control and protection

current and voltage. On the other hand, a well-designed control strategy can make the fault characteristics much more significant to facilitate fault detection and protection. Especially in IT grounding systems, the superiority of the method will be well embodied. As shown in Fig. 11, the coordinated strategy of control and protection is more effective than traditional stand alone protection schemes. The control strategy becomes the first line of defense for
DC microgrids and helps to realize fault detection and isolation to ensure system security. The immediate control segment responses following the fault and different strategies will be adopted according to whether the fault characteristics are significant.

\section{Conclusion}

This paper presents the current research status on relative issues of DC microgrids and reviews the proposed protection strategies. The concept of DC microgrids, including distributed generators, converters, storage batteries and various loads, is introduced. The fault current quickly increases with large peaks due to low fault impedance, which means that fault detection and isolation should be performed as soon as possible. The current protection systems have been presented in detail including protection devices, grounding options and protection principles and schemes. These aforementioned contents cannot completely satisfy the protection requirements for DC microgrids. Lacking effective overall protection systems restricts the development and promotion of DC 
microgrids. Several key lines of protection research prospects can be pointed out. Novel protection devices meeting the technical and economic requirements should continue to be studied and developed. The influence of different grounding methods should be analyzed. Only then can a widely accepted grounding method for DC microgrids be determined. Novel protection schemes are still in demand to realize fast and accurate fault detection and isolation. Meanwhile, the protection coordination of upstream and downstream devices will be an important research topic in the future. With the development of DC microgrids that contain a large amount of electronic devices, the concept of protection could be extended. The control strategy will be the first line of defense for DC microgrids in response to short-circuit faults. As a result, the coordinated strategy of control and protection could be more effective than considering traditional protection schemes by themselves.

Open Access This article is distributed under the terms of the Creative Commons Attribution 4.0 International License (http:// creativecommons.org/licenses/by/4.0/), which permits unrestricted use, distribution, and reproduction in any medium, provided you give appropriate credit to the original author(s) and the source, provide a link to the Creative Commons license, and indicate if changes were made.

\section{References}

[1] Hatziargyriou N, Asano H, Iravani R et al (2007) Microgrids. IEEE Power Energy Mag 5(4):78-94

[2] Ding G, Gao F, Zhang S et al (2014) Control of hybrid AC/DC microgrid under islanding operational conditions. J Mod Power Syst Clean Energy 2(3):223-232

[3] Salomonsson D, Soder L, Sannino A (2009) Protection of lowvoltage DC microgrids. IEEE Trans Power Deliv 24(3):1045-1053

[4] Fletcher SDA, Norman PJ, Galloway SJ et al (2012) Optimizing the roles of unit and non-unit protection methods within DC microgrids. IEEE Trans Smart Grid 3(4):2079-2087

[5] AlLee G, Tschudi W (2012) Edison redux: 380 Vdc brings reliability and efficiency to sustainable data centers. IEEE Power Energy Mag 10(6):50-59

[6] Rodriguez-Diaz E, Chen F, Vasquez JC et al (2016) Voltagelevel selection of future two-level LVdc distribution grids: a compromise between grid compatibility, safety and efficiency. IEEE Electrif Mag 4(2):20-28

[7] Hooshyar A, Iravani R (2017) Microgrid protection. Proc IEEE 105(7):1332-1353

[8] Huang AQ, Crow ML, Heydt GT et al (2011) The future renewable electric energy delivery and management (FREEDM) system: the energy internet. Proc IEEE 99(1):133-148

[9] Bifaretti S, Zanchetta P, Watson A et al (2011) Advanced power electronic conversion and control system for universal and flexible power management. IEEE Trans Smart Grid 2(2):231-243

[10] Liserre M (2015) HEART-The highly efficient and reliable smart transformer. http://www.pe.tf.uni-kiel.de/en/staff/ professors/prof.-dr.-ing.-marco-liserre/presentation_sonderborg
[11] Dragicevic T, Lu X, Vasquez JC et al (2016) DC microgridspart II: a review of power architectures, applications and standardization issues. IEEE Trans Power Electron 31(5):3528-3549

[12] ETSI EN 300 132-3-1 (2011) Environmental engineering (EE), power supply interface at the input to telecommunications and datacom (ICT) equipment, part 3: operated by rectified current source, alternating current source or direct current source up to $400 \mathrm{~V}$, sub-part 1: direct current source up to $400 \mathrm{~V}$. http://www. etsi.org/deliver/etsi_en/300100_300199/3001320301/02.01.01_40/ en_3001320301v020101o.pdf

[13] IEEE recommended practice for the design of DC auxiliary power systems for generating stations (1993) IEEE Std 946-1992:1-35

[14] IEC - standardization management board-SG4 LVDC distribution systems up to $1500 \mathrm{~V}$ DC (2009) http://www.iec.ch/dyn/ www/f?p=103:85:0::::FSP_ORG_ID:6019

[15] Park JD, Candelaria J, Ma L et al (2013) DC ring-bus microgrid fault protection and identification of fault location. IEEE Trans Power Deliv 28(4):2574-2584

[16] Li YW, Nejabatkhah F (2014) Overview of control, integration and energy management of microgrids. J Mod Power Syst Clean Energy 2(3):212-222

[17] Kusko A, Dedad J (2007) Stored energy—short-term and longterm energy storage methods. IEEE Ind Appl Mag 13(4):66-72

[18] Meng L, Shafiee Q, Trecate GF et al (2017) Review on control of DC microgrids and multiple microgrid clusters. IEEE J Emerg Sel Top Power Electron 5(3):928-948

[19] Olivares DE, Mehrizi-Sani A, Etemadi AH et al (2014) Trends in microgrid control. IEEE Trans Smart Grid 5(4):1905-1919

[20] Jin C, Wang P, Xiao J et al (2014) Implementation of hierarchical control in DC microgrids. IEEE Trans Ind Electron 61(8):4032-4042

[21] Li J, Yang Q, Robinson F et al (2017) Design and test of a new droop control algorithm for a SMES/battery hybrid energy storage system. Energy 118:1110-1122

[22] Li J, Xiong R, Yang Q et al (2016) Design/test of a hybrid energy storage system for primary frequency control using a dynamic droop method in an isolated microgrid power system. Appl Energy 201:257-269

[23] Park JD, Candelaria J (2013) Fault detection and isolation in low-voltage DC-bus microgrid system. IEEE Trans Power Deliv 28(2):779-787

[24] Fletcher SDA, Norman PJ, Galloway SJ et al (2011) Determination of protection system requirements for DC unmanned aerial vehicle electrical power networks for enhanced capability and survivability. IET Electr Syst Transp 1(4):137-147

[25] Yang J, Fletcher JE, O'Reilly J (2010) Multiterminal DC wind farm collection grid internal fault analysis and protection design. IEEE Trans Power Deliv 25(4):2308-2318

[26] Cuzner RM, Venkataramanan G (2008) The status of DC microgrid protection. In: Proceedings of the 2008 IEEE industry applications society annual meeting, Edmonton, Alta., Canada, 5-9 October 2008, pp 1-8

[27] Meyer C, Schroder S, De Doncker RW (2004) Solid-state circuit breakers and current limiters for medium-voltage systems having distributed power systems. IEEE Trans Power Electron 19(5):1333-1340

[28] Lawes D, Ran L, Xu Z (2014) Design of a solid-state D.C. circuit breaker for light rail transit power supply network. In: Proceedings of the 2014 IEEE energy conversion congress and exposition (ECCE), Pittsburgh, USA, 14-18 September 2014, pp 350-357

[29] Zheng H, Lin H, Du Y (2015) Designing and research of a novel current limiting DC hybrid circuit breaker with the combinatorial electronic switch. In: Proceedings of the 2015 IEEE 
innovative smart grid technologies-Asia (ISGT ASIA), Bangkok, Thailand, 3-6 November 2015, pp 1-5

[30] Wen W, Huang Y, Sun Y et al (2016) Research on current commutation measures for hybrid DC circuit breakers. IEEE Trans Power Deliv 31(4):1456-1463

[31] Bucher MK, Walter MM, Pfeiffer M et al (2012) Options for ground fault clearance in HVDC offshore networks. In: Proceedings of the 2012 IEEE energy conversion congress and exposition (ECCE), Raleigh, USA, 15-20 September 2012, pp 2880-2887

[32] Heidemann M, Nikolic G, Schnettler A et al (2016) Circuitbreakers for medium-voltage DC grids. In: Proceedings of the 2016 IEEE PES transmission and distribution conference and exposition-Latin America (PES T\&D-LA), Morelia, Mexico, 20-24 September 2016, pp 1-6

[33] Mobarrez M, Kashani MG, Bhattacharya S et al (2014) Comparative study of DC circuit breakers using real-time simulations. In: Proceedings of the 40th annual conference of the IEEE industrial electronics society (IECON 2014), Dallas, USA, 29 October-1 November 2014, pp 3736-3742

[34] Shen ZJ, Miao Z, Roshandeh AM (2015) Solid state circuit breakers for DC micrgrids: current status and future trends. In: Proceedings of the 2015 IEEE first international conference on DC microgrids (ICDCM), Atlanta, USA, 7-10 June 2015, pp 228-233

[35] Urciuoli DP, Veliadis V, Ha HC et al (2011) Demonstration of a $600 \mathrm{~V}, 60 \mathrm{~A}$, bidirectional silicon carbide solid-state circuit breaker. In: Proceedings of the 2011 twenty-sixth annual IEEE applied power electronics conference and exposition (APEC), Fort Worth, USA, 6-11 March 2011, pp 354-358

[36] Sato Y, Tanaka Y, Fukui A et al (2014) SiC-SIT circuit breakers with controllable interruption voltage for $400 \mathrm{~V}$ DC distribution system. IEEE Trans Power Electron 29(5):2597-2605

[37] Miao Z, Sabui G, Chen A et al (2015) A self-powered ultra-fast DC solid state circuit breaker using a normally-on SiC JFET. In: Proceedings of the 2015 IEEE applied power electronics conference and exposition (APEC), Charlotte, USA, 15-19 March 2015, pp 767-773

[38] Shen ZJ, Roshandeh AM, Miao Z et al (2015) Ultrafast autonomous solid state circuit breakers for shipboard DC power distribution. In: Proceedings of the 2015 IEEE electric ship technologies symposium (ESTS), Alexandria, USA, 21-24 June 2015, pp 299-305

[39] Urciuoli DP, Ibitayo D, Koebke G et al (2016) A compact 100 A, $850 \mathrm{~V}$, silicon carbide solid-state DC circuit breaker. In: Proceedings of the 2016 IEEE energy conversion congress and exposition (ECCE), Milwaukee, USA, 18-22 September 2016, pp 1-5

[40] Peng C, Song X, Rezaei MA et al (2014) Development of medium voltage solid-state fault isolation devices for ultra-fast protection of distribution systems. In: Proceedings of the 40th annual conference of the IEEE industrial electronics society (IECON 2014), Dallas, USA, 29 October-1 November 2014, pp 5169-5176

[41] Peng C, Song X, Huang AQ et al (2017) A medium-voltage hybrid DC circuit breaker-part II: ultrafast mechanical switch. IEEE J Emerg Sel Top Power Electron 5(1):289-296

[42] Paul D (2002) DC traction power system grounding. IEEE Trans Ind Appl 38(3):818-824

[43] Baran ME, Mahajan NR (2002) DC distribution for industrial systems: opportunities and challenges. IEEE Trans Ind Appl 39(6): 1596-1601

[44] Park J (2015) Ground fault detection and location for ungrounded DC traction power systems. IEEE Trans Veh Technol 64(12):5667-5676
[45] Valdes M, Papallo T, Premerlani B (2007) Finding fault-locating a ground fault in low-voltage, high-resistance grounded systems via the single-processor concept for circuit protection. IEEE Ind Appl Mag 13(5):24-30

[46] Yang J, Fletcher JE, O'Reilly J (2012) Short-circuit and ground fault analyses and location in VSC-based DC network cables. IEEE Trans Ind Electron 59(10):3827-3837

[47] Jacobson B, Walker J (2007) Grounding considerations for DC and mixed DC and AC power systems. Naval Eng J 119(2):49-62

[48] IEC 60364-1 Low-voltage electrical installations-part 1: fundamental principles, assessment of general characteristics, definitions, IEC 60364-1, 2005, https://webstore.iec.ch/publication/ $1865 \&$ preview $=1$

[49] Lee CH, Lu CJ (2006) Assessment of grounding schemes on rail potential and stray currents in a DC transit system. IEEE Trans Power Deliv 21(4):1941-1947

[50] Bam L, Jewell W (2005) Review: power system analysis software tools. In: Proceedings of the IEEE power engineering society general meeting, San Francisco, USA, 16-16 June 2005, pp 139-144

[51] Power system analytical software tools. http://www.itee.uq.edu. au/pssl/drupal7_with_innTheme/?q=node/34

[52] Venayagamoorthy GK (2005) Comparison of power system simulation studies on different platforms-RSCAD, PSCAD/ EMTDC, and SIMULINK SimPowerSystems. In: Proceedings of the international conference on power system operations and planning (ICPSOP), Praia, Cape Verde, 22-26 May 2005, pp 38-41

[53] A review of power system modelling platforms and capabilities (2015) http://www.theiet.org/sectors/energy/documents/ modelling-3.cfm?type $=$ pdf

[54] Xue S, Chen C, Jin Y et al (2014) Protection for DC distribution system with distributed generator. J Appl Math 7:1-12

[55] Meghwani A, Srivastava S, Chakrabarti S (2017) A non-unit protection scheme for DC microgrid based on local measurements. IEEE Trans Power Deliv 32(1):172-181

[56] Baran ME, Mahajan NR (2007) Overcurrent protection on voltage-source-converter-based multiterminal DC distribution systems. IEEE Trans Power Deliv 22(1):406-412

[57] Meghwani A, Srivastava SC, Chakrabarti S (2015) A new protection scheme for DC microgrid using line current derivative. In: Proceedings of the 2015 IEEE power and energy society general meeting, Denver, USA, 26-30 July 2015, pp 1-5

[58] Mollet R (1995) Overcurrent protection of DC power plant equipment using modern high performance current limiting fuses. In: Proceedings of the 17th international telecommunications energy conference (INTELEC 95), The Hague, the Netherlands, 29 October-1 November 1995, pp 379-383

[59] Jin C, Dougal R (2006) Current limiting technique based protection strategy for an industrial DC distribution system. In: Proceedings of the 2006 IEEE international symposium on industrial electronics, Montreal, Canada, 9-13 July 2006, pp 820-825

[60] Munasib S, Balda JC (2016) Short-circuit protection for lowvoltage DC microgrids based on solid-state circuit breakers. In: Proceedings of the 2016 IEEE 7th international symposium on power electronics for distributed generation systems (PEDG), Vancouver, Canada, 27-30 June 2016, pp 1-7

[61] Xue S, Gao F, Sun W et al (2015) Protection principle for a DC distribution system with a resistive superconductive fault current limiter. Energies 8(6):4839-4852

[62] Mitra P, Wikströ MC, Johannesson N et al (2015) First real-time implementation of DC grid protection strategy. In: Proceedings of the 11th IET international conference on AC and DC power transmission, Birmingham, UK, 10-12 February 2015, pp 1-8 
[63] Leterme W, Beerten J, Van Hertem D (2016) Non-unit protection of HVDC grids with inductive dc cable termination. IEEE Trans Power Deliv 32(2):820-828

[64] Rezaei N, Haghifam MR (2008) Protection scheme for a distribution system with distributed generation using neural networks. Int J Electr Power Energy Syst 30(4):235-241

[65] Zayandehroodi H, Mohamed A, Shareef H et al (2012) A novel neural network and backtracking based protection coordination scheme for distribution system with distributed generation. Int $\mathbf{J}$ Electr Power Energy Syst 43(1):868-879

[66] Javadian SAM, Haghifam MR, Bathaee SMT et al (2013) Adaptive centralized protection scheme for distribution systems with DG using risk analysis for protective devices placement. Int J Electr Power Energy Syst 44(1):337-345

[67] Chanda NK, Fu Y (2011) ANN-based fault classification and location in MVDC shipboard power systems. In: Proceedings of the North American power symposium (NAPS), Boston, USA, 4-6 August 2011, pp 1-7

[68] Yang Q, Le Blond S, Aggarwal R et al (2017) New ANN method for multi-terminal HVDC protection relaying. Electr Power Syst Res 148:192-201

[69] Monadi M, Zamani MA, Candela JI et al (2015) Protection of $\mathrm{AC}$ and DC distribution systems embedding distributed energy resources: a comparative review and analysis. Renew Sustain Energy Rev 51:1578-1593

[70] Venkataramanan G, Marnay C (2008) A larger role for microgrids. IEEE Power Energy Mag 6(3):78-82

[71] Sood VK, Fischer D, Eklund JM et al (2009) Developing a communication infrastructure for the smart grid. In: Proceedings of the 2009 IEEE electrical power and energy conference (EPEC), Montreal, USA, 22-23 October 2009, pp 1-7

[72] ALSTOM (2011) Unit protection of feeders. In: Network protection and automation guide ALSTOM, 10. https://zh.scribd. com/doc/120022911/Alstom-Network-Protection-and-Automa tion-Guide-2011

[73] Monadi M, Koch-Ciobotaru C, Luna A et al (2014) A protection strategy for fault detection and location for multi-terminal MVDC distribution systems with renewable energy systems. In: Proceedings of the 2014 international conference on renewable energy research and application (ICRERA), Milwaukee, USA, 19-22 October 2014, pp 496-501

[74] Emhemed AAS, Burt GM (2014) An advanced protection scheme for enabling an LVDC last mile distribution network. IEEE Trans Smart Grid 5(5):2602-2609

[75] Farhadi M, Mohammed OA (2015) Event-based protection scheme for a multiterminal hybrid DC power system. IEEE Trans Smart Grid 6(4):1658-1669

[76] Pradeep Y, Khaparde SA, Joshi RK (2012) High level event ontology for multiarea power system. IEEE Trans Smart Grid 3(1):193-202

[77] Fariba L, Hossien S (2013) An economic-based special protection system in a restructured environment. Electr Power Compon Syst 41(15):1536-1554

[78] Tang L, Ooi BT (2007) Locating and isolating DC faults in multi-terminal DC systems. IEEE Trans Power Deliv 22(3):1877-1884

[79] Yu M, Wang Y, Zhang L et al (2016) DC short circuit fault analysis and protection of ring type DC microgrid. In: Proceedings of the 2016 IEEE 8th international power electronics and motion control conference (IPEMC-ECCE Asia), Hefei, China, 22-26 May 2016, pp 1694-1700

[80] Fletcher SDA, Norman PJ, Fong K et al (2014) High-speed differential protection for smart DC distribution systems. IEEE Trans Smart Grid 5(5):2610-2617

[81] Villamagna N, Crossley PA (2008) A symmetrical componentbased GPS signal failure-detection algorithm for use in feeder current differential protection. IEEE Trans Power Deliv 23(4):1821-1828

[82] Farhadi M, Mohammed OA (2016) A new protection scheme for multi-bus DC power systems using an event classification approach. IEEE Trans Ind Appl 52(4):2834-2842

[83] Yuan C, Haj-Ahmed MA, Illindala MS (2015) Protection strategies for medium voltage direct current microgrid at a remote area mine site. IEEE Trans Ind Appl 51(4):2846-2853

[84] Li L, Ma P, Wang Y (2008) A novel method for DC system grounding fault monitoring on-line and its realization. In: Proceedings of the 2008 IEEE international conference on automation and logistics, Qingdao, China, 1-3 September 2008, pp 1813-1816

[85] Chew SH, Tseng KJ (2016) A line to ground fault detection technique for ELVDC distribution system in built environment. In: Proceedings of the 2016 IEEE 7th international symposium on power electronics for distributed generation systems (PEDG), Vancouver, Canada, 27-30 June 2016, pp 1-7

[86] Dong CY, He JH, Wang XK et al (2012) High-resistance grounding fault detection and location in DC railway system. In: Proceedings of the 11th IET international conference on developments in power systems protection (DPSP 2012), Birmingham, UK, 23-26 April 2012, pp 1-5

[87] Kontos E, Pinto RT, Bauer P (2014) Effect of power flow control methods on the DC fault response of multi-terminal DC networks. In: Proceedings of the 40th annual conference of the IEEE industrial electronics society (IECON 2014), Dallas, USA, 29 October-1 November 2014, pp 2075-2081

[88] Li A, Cai Z, Sun Q et al (2009) Study on the dynamic performance characteristics of HVDC control and protections for the HVDC line fault. In: Proceedings of the 2009 IEEE power and energy society general meeting, Calgary, Canada, 26-30 July 2009, pp 1-5

[89] Dhar S, Patnaik RK, Dash PK (2017) Fault detection and location of photovoltaic based DC microgrid using differential protection strategy. IEEE Trans Smart Grid. https://doi.org/10. 1109/TSG.2017.2654267

[90] Feng L, Gou R, Zhuo F et al (2016) Development of a $10 \mathrm{kV}$ solid-state DC circuit breaker based on press-pack IGBT for VSC-HVDC system. In: Proceedings of the 2016 IEEE 8th international power electronics and motion control conference (IPEMC-ECCE Asia), Hefei, China, 22-26 May 2016, pp 2371-2377

[91] Kim JY, Choi SS, Song SM et al (2016) New DC solid state circuit breaker with reclosing and rebreaking capabilities. In: Proceedings of the 2016 IEEE 8th international power electronics and motion control conference (IPEMC-ECCE Asia), Hefei, China, 22-26 May 2016, pp 3554-3558

[92] Wang C, Li X, Guo L et al (2014) A nonlinear-disturbanceobserver-based DC-bus voltage control for a hybrid AC/DC microgrid. IEEE Trans Power Electron 29(11):6162-6617

Lin ZHANG received the B.Sc. degree in Zhejiang University, Hangzhou, China, in 2015 and now he is a master degree candidate of electrical engineering at Shanghai Jiao Tong University, Shanghai, China. His research interests are the protection and control of DC microgrids.

Nengling TAI received the B.Sc., M.Sc., and Ph.D. degrees in electrical engineering from Huazhong University of Science and Technology (HUST), Wuhan, China, in 1994, 1997, and 2000, respectively. Currently, he is a professor with the Department of Power Electrical Engineering, Shanghai Jiao Tong University, China. His research interest is power system protection. 
Wentao HUANG received the B.Sc. degree in electrical engineering from Shanghai Jiao Tong University, Shanghai, China, in 2010, where he is currently pursuing the Ph.D. degree in electrical engineering. His research interests are the protection and control of active distribution systems, microgrids, smart grid and renewable energy.

Jian LIU received the B.S. degree in South China University of Technology, Guangzhou, China, in 2012 and now he is a Ph.D. candidate of electrical engineering at Shanghai Jiao Tong University, Shanghai, China. His research interests are the protection and control of HVDC, VSC-HVDC transmission system and HVDC grids.

Yanhong WANG received the B.Sc. degree in Shanghai Jiao Tong University, Shanghai, China, in 2014 and now she is a master degree candidate of electrical engineering at Shanghai Jiao Tong University, Shanghai, China. Her research interest is renewable energy. 